\title{
MudanÇA EM PSiCOTERAPIA DE GRUPO: REFLEXÕES A PARTIR DA TERAPIA NARRATIVA ${ }^{\mathrm{I}}$
}

\author{
Rafael Santos Carrijo* \\ Emerson Fernando Rasera**
}

\section{Resumo}

Este estudo de caso visa compreender o processo de mudança de uma pessoa em psicoterapia de grupo a partir de uma perspectiva narrativa. A observação participante e a análise dos registros das doze sessões de um grupo de curto prazo permitiram investigar episódios e intervenções terapêuticas que contribuíram para a construção de uma narrativa em que a pessoa se descrevia com uma maior autonomia em sua vida, superando a narrativa anterior saturada pelo problema. Entendemos que os recursos propostos pela perspectiva narrativa, tais como a identificação de acontecimentos extraordinários, a externalização do problema e o fortalecimento das narrativas de enfrentamento ajudaram a construir novos sentidos por meio da criação de um espaço dialógico no contexto grupal. Apesar da fertilidade da aproximação das propostas narrativas ao campo grupal, as reflexões realizadas apontaram ainda alguns desafios a serem enfrentados.

Palavras-chave: psicoterapia de grupo, terapia narrativa, mudança, construcionismo social.

\section{Abstract}

CHANGE IN GROUP PSYCHOTHERAPY: UNDERSTANDINGS FROM NARRATIVE THERAPY

This case study aims to understand the change process of a person in group psychotherapy, from a narrative perspective. Participant observation and an analysis of the notes of twelve sessions of a short-term group allowed us to investigate episodes and therapeutic interventions that had contributed to the construction of a narrative in which the person self-described as

* Mestrando em Psicologia Aplicada pela Universidade Federal de Uberlândia (UFU).

** Doutor em Psicologia pela Universidade de São Paulo (USP); Professor de Psicologia da Universidade Federal de Uberlândia (UFU). 
more autonomous, surpassing the previous narrative saturated by the problem. It was observed that narrative resources such as, the identification of unique outcomes, externalizing the problem and the reinforcement of confrontational narratives have helped to construct new meanings through the creation of a dialogical space in the group context. In spite of the fertility of the use of narrative proposals in the group field, our reflections pointed out some challenges to be faced in this approach.

Keywords: group therapy, narrative therapy, change process, social construction.

Este artigo apresenta um estudo de caso de um atendimento em psicoterapia de grupo orientado por uma perspectiva construcionista social, especificamente pelos pressupostos da terapia narrativa. Assim, contamos a história de mudança de uma pessoa numa situação de atendimento em terapia de grupo e refletimos sobre as possibilidades de intervenção da terapia narrativa a partir de alguns episódios do atendimento realizado.

Apresentar experiências profissionais como esta pode ser fundamental para proporcionar a construção de novos sentidos e jeitos de se atuar no âmbito da terapia em grupo, uma vez que a prática clínica tem sido um importante contexto de geração de conhecimentos. Além disso, de acordo com Rasera e Japur (2001), apesar de serem múltiplas as contribuiçôes do construcionismo para o campo da psicoterapia individual e familiar, ainda são raros os trabalhos que apresentam tais contribuições para o contexto de psicoterapia de grupo. Da mesma forma, também são escassos os estudos na literatura científica referentes às contribuições da terapia narrativa no Brasil.

\section{Terapia narrativa: UMA ElaboraÇÃo CONSTRUCIONISTA DA PRÁtica CLÍNICA}

O Construcionismo Social é uma perspectiva teórica pós-moderna que, diferentemente de epistemologias tradicionais, explica o processo de significação e construção de sentidos por meio dos processos de interação humana (Spink, 2003). Assim, para o Construcionismo sujeito e objeto são construções sócio-históricas que precisam ser problematizadas e desnaturalizadas.

No âmbito da psicoterapia, a utilização das ideias construcionistas tem sido realizada por meio de intervenções que propõem novas descrições de problema, de mudança e de si mesmo a partir de uma ênfase na linguagem. Assim, o que chamamos de "problema" e "mudança" é marcado pelas formas linguísticas (nomes, 
palavras, expressões, etc) que usamos para descrever o mundo e nossas experiências, as quais são estruturadas histórico-culturalmente (Rasera \& Japur, 2007).

A terapia narrativa é uma prática que tem sido proposta e refletida em muitos trabalhos nos últimos anos (Freedman \& Combs, 1996; White \& Epston, 1990; White, 1995, 2007). Ela pode ser compreendida como uma perspectiva terapêutica pautada por influências construcionistas sociais à medida que propõe que é por meio da linguagem como prática social que significamos e organizamos as nossas relações. Para White e Epston (1990), as terapias narrativas focam-se na compreensão de como a experiência das pessoas é narrada e de como essas narrativas dão sentido e constituem as experiências.

Segundo Gergen (1997), as narrações não são posses do indivíduo, mas das suas relações, que estão inscritas num sistema social e histórico. Nesta perspectiva, as narrações não são a expressão do nosso mundo interno, mas opções discursivas, formas sociais de significarmos as nossas experiências e de organizarmos as nossas ações. Para o autor, a maneira que nos descrevemos ou narramos as nossas histórias pode ajudar ou dificultar a busca por novas soluçôes para nossos problemas.

De acordo com White (2000), não é apenas a nossa experiência que estrutura a nossa expressão, a nossa expressão também estrutura a nossa experiência. Ou seja, as histórias que contamos sobre nós mesmos podem dar sentido para as nossas vidas e as nossas relações, modificando-as. Por isso, de acordo com as teorias construcionistas, a psicoterapia é um processo de mudar o discurso "problemático" por um outro mais fluido que permita à pessoa se relacionar melhor consigo mesma, sua vida, bem como com outras pessoas (Lax, 1998). Assim, a mudança neste contexto é compreendida como um processo em que as pessoas passam a utilizar narrativas preferíveis sobre si mesmas e suas vidas.

Considerando a ênfase construcionista da polivocalidade, Epston, White e Murray (1998) apontam que as histórias que contamos sobre nós mesmos têm um caráter indeterminado e são revestidas de contradições e ambiguidades. Para estes autores, existem momentos em que as narrações e as experiências não se encaixam, não se conectam, deixando lacunas, espaços entre os discursos e aquilo que vivenciamos. Estes momentos são chamados de "acontecimentos extraordinários", que "incluem toda gama de acontecimentos, sentimentos, intenções, pensamentos, ações, etc. que têm uma localização histórica, presente ou futura, e que o relato dominante não pode incorporar” (White \& Epston, 1990: 32).

Quando aqueles autores discutem a construção dos discursos dominantes, eles se baseiam na proposta de Foucault sobre a produção do conhecimento e do poder. Segundo White e Epston (1990: 85-86), Foucault acredita que, “através do poder, as pessoas se submetem a verdades normalizadoras que prejudicam suas vidas e 
suas relações”. Desta forma, estas verdades são produzidas e geram a construção de normas, padrões, maneiras de ver, sentir, pensar e agir sobre o mundo de tal forma que passamos a organizar as nossas relaçôes por meio delas. Assim, por meio das verdades normalizadoras, deixamos de narrar alguns aspectos da nossa experiência, pois estes não se encaixam no padrão proposto por essas verdades.

$\mathrm{Na}$ terapia narrativa, objetiva-se separar linguisticamente a pessoa do seu problema; para isso, o terapeuta busca produzir a "externalização do problema". Nessa prática, compreende-se que não são as pessoas nem suas relações que constituem o problema, mas sim o sentido que as pessoas dão para algumas situações de suas vidas (White \& Epston, 1990). Em outras palavras, é a relação das pessoas com determinados aspectos de suas vidas que os torna um problema.

White e Epston (1990), em busca da separação entre as pessoas e os seus problemas, propõem um modelo que ajuda as pessoas a criarem histórias alternativas. Este modelo consiste no terapeuta utilizar "perguntas de influência relativa", em que num primeiro momento busca-se entender a influência do problema sobre a vida da pessoa e, posteriormente, a influência da pessoa sobre a vida do problema. Assim, por meio da definição do problema e deste jeito de se perguntar, o terapeuta busca identificar os "acontecimentos extraordinários", que podem estar no passado, no presente ou no futuro.

Neste processo de "externalização do problema", de reflexão proposta pelas perguntas de influência relativa e de identificação de "acontecimentos extraordinários", a pessoa redescreve a sua relação com o problema, o que lhe ajuda a reformular a sua relação consigo mesma. Assim, de uma história saturada pelo problema pode-se passar para uma história em que a pessoa se sente como responsável pelas próprias narrações, como agente da própria vida, com capacidades de agir e mudar o mundo (Rasera \& Japur, 2004).

Uma outra prática proposta por White e Epston (1990) é a utilização de cartas terapêuticas. Segundo os autores, elas representam uma outra forma de se realizar intervenções, em que o objetivo é transformar experiências pessoais em descrições, de forma que, ao escrever sobre as histórias em forma de carta, o terapeuta possa ajudar, gradativamente, as pessoas a transformarem as suas narrativas. Este processo consiste no terapeuta convidar a pessoa a re-pensar sua história, se separar dos seus problemas e explorar melhor os "acontecimentos extraordinários", de forma que ela reflita sobre sua experiência, reorganizando-a e reconstruindo-a.

Neste processo em que as pessoas passam a reconhecer "acontecimentos extraordinários” e criar novas explicações e descriçōes que podem contribuir para a construção de novas narrativas, o terapeuta pode ajudar a pessoa a fortalecer essas narrativas de forma a que estas possam ser legitimadas e o cliente passe a criar um 
lugar diferente para si mesmo nas suas relações e na sua vida. Segundo Rasera e Japur (2007), nos encontros finais do grupo as conversas de legitimação das narrativas de enfrentamento geradas no contexto grupal representam uma forma de finalizá-los. Além disso, este tipo de conversa contribui para dar visibilidade, tanto para o terapeuta como para seus clientes, de todo processo de construção e de fortalecimento da mudança.

Conforme pudemos perceber, existem várias possibilidades para a aplicação das ideias narrativas em um contexto de atuação clínica, porém ainda são poucos os trabalhos científicos que relatam a utilização desta modalidade de terapia com grupos. Entre os trabalhos existentes, destacam-se o de Laube e Treftz (2004), que descrevem a possibilidade de questionar a narrativa socialmente dominante da depressão no grupo, e o de Chen, Noosbond e Bruce (1998), que apontam o uso terapêutico das cartas no contexto grupal. Apesar dessas iniciativas, ainda são necessários vários esforços para aproximar o campo da terapia narrativa ao das práticas grupais.

\section{OBjetivo}

O objetivo deste estudo é compreender o processo de mudança em psicoterapia de grupo a partir das transformaçóes das narrativas de si mesmo de um participante, bem como dar visibilidade às formas de utilização das propostas de terapia narrativa no contexto da prática grupal.

\section{MÉTOdo}

\section{CONTEXTO}

O presente trabalho conta a história de um atendimento realizado na Clínica Psicológica de uma universidade pública mineira. $\mathrm{O}$ modelo de atendimento em grupo, de base construcionista social, foi influenciado pelas contribuiçôes da terapia narrativa, da abordagem colaborativa e dos processos reflexivos, tal como apresentado por Rasera e Japur (2007). A prática realizada apoiou-se na criação de um contexto de conversação de base dialógica em que o terapeuta se colocou enquanto um parceiro de conversação, contribuindo para a criação de narrativas de mudança. O grupo foi de curto prazo, com doze sessões de uma hora e meia de duração, e contou com a participação de sete pessoas. $\mathrm{O}$ atendimento foi 
realizado por quatro terapeutas, organizados em duas duplas, como terapeutas de campo e equipe reflexiva, e contou com a participação de um supervisor. Os terapeutas de campo lidavam diretamente com os participantes e buscavam atuar com o objetivo de criar condições conversacionais que facilitassem a produção de novos entendimentos sobre as coisas e as pessoas. A equipe reflexiva, por sua vez, assistia silenciosamente a conversação terapêutica e, quando convidada pelos terapeutas de campo, compartilhava suas impressões e questionamentos com os participantes do grupo.

\section{ESCOLHA DO CASO ANALISADO}

Escolhemos o caso analisado devido a alguns motivos: a) o cliente chegou à terapia com uma descrição crônica dos seus problemas, em uma típica narrativa saturada pelo problema; b) ele tinha um jeito peculiar de estar na terapia, pois se mantinha quieto e pensativo na maior parte das sessões e, algumas vezes, chegou atrasado, com um padrão de engajamento terapêutico, para nós, pouco claro; e c) ao término do atendimento, a pessoa atendida estava empregada, estudando e descobriu que possuía recursos que poderiam lhe ajudar a transformar sua vida, se tornando uma pessoa mais autônoma e constituindo um caso de sucesso no grupo. Após a seleção do caso, utilizamos os registros de cada sessão para que pudéssemos refletir sobre o processo de mudança desta pessoa em atendimento.

\section{CONSTRUÇÃO DO CASO}

Considerando que uma mesma pessoa pode apresentar várias narrativas ao longo de um atendimento clínico, selecionamos quatro episódios narrativos que consideramos significativos para dar visibilidade ao processo de mudança de uma pessoa em atendimento em grupo. Em cada um destes, descrevemos brevemente o contexto das conversas, a interação entre os participantes, a intervenção realizada e as implicações destas na construção de novas narrativas.

\section{Cuidados ÉtICOS}

Este trabalho respeitou todos os procedimentos éticos, contando com a leitura e autorização voluntária da pessoa atendida para a publicação deste artigo. A 
fim de se preservar sua identidade, utilizaremos um nome fictício ao longo deste trabalho - Daniel.

\section{A HISTÓRIA DE DANIEL NAS SESSÕES DE TERAPIA}

Daniel tinha 26 anos, era solteiro e procurou espontaneamente o atendimento. Nas entrevistas iniciais, contou que vivenciou um problema de saúde que fez com que sua família passasse a assumir uma postura de cuidado excessivo com ele, limitando sua autonomia. Assim, buscava na terapia uma forma de melhorar a sua vida, que estava "parada". Na primeira sessão do grupo, ele se descreveu como uma pessoa sem autoestima, depressivo, com dificuldades de expressar suas próprias opiniōes e de se relacionar com outras pessoas. Durante a segunda sessão, Daniel nos contou sobre uma situação em que colocou um piercing sem consultar sua família. Na terceira e na quarta sessões, ficou a maior parte do tempo calado, fazendo breves comentários sobre algumas de suas questões. Na quinta sessão, a carta terapêutica destacava o fato de Daniel ter colocado um piercing e como isto podia representar uma afirmação da sua vontade. Ele contou, na sexta sessão, que a terapia estava lhe ajudando, deixando-o mais leve. Nas duas sessões seguintes, chegou com meia hora de atraso. Na oitava sessão, Daniel falou como era difícil se relacionar com outras pessoas. Na nona sessão, comentou que estava aprendendo a colocar mais as suas opiniōes, que estava ouvindo as pessoas, mas não aceitando tudo que lhe falavam. Depois de ausentar-se na décima sessão, na sessão seguinte destaca que sua vida estava mais movimentada e que estava fazendo novos cursos. $\mathrm{Na}$ última sessão, Daniel afirmou que o ato de refletir sobre a própria vida lhe ajudou a mudar. Contou também que sua família estava percebendo que ele estava mais independente, com mais perspectivas e projetos para o futuro. Após quatro meses do atendimento em grupo, em uma entrevista de acompanhamento, Daniel comentou que estava bem, empregado, estudando e satisfeito com os resultados da terapia na sua vida.

\section{DOS RECURSOS NÃO NARRADOS A “MUDANÇA DA MUDANÇA”}

Daniel começou a terapia com uma narrativa, saturada por problemas, que estava focada na falta de perspectiva e planos para o futuro. A terapia, numa perspectiva narrativa, consiste num processo em que o terapeuta se engaja por meio da conversação a fim de facilitar e cocriar com seu cliente novas narrativas, que poderão criar novos sentidos para as experiências vividas pelas pessoas em aten- 
dimento (Lax, 1998). Assim, nesta análise foram selecionados alguns episódios e as respectivas intervençōes que, no nosso entendimento, contribuíram para o processo de mudança de Daniel. Quando for usada a primeira pessoa do singular, o texto refere-se às intervençōes realizadas pelo coordenador do grupo, primeiro autor deste trabalho.

\section{“O DIA DO PIERCING”: IDENTIFICANDO UM ACONTECIMENTO EXTRAORDINARIO PASSADO}

Nas entrevistas iniciais para composição do grupo, Daniel havia contado que estava sem emprego e sem estudar. Porém, após as sessões individuais, logo no início do grupo, o participante arrumou emprego em um estabelecimento comercial, o que lhe garantiu uma renda pessoal. Desta forma, na segunda sessão de terapia, Daniel apresentou ao grupo a sua vontade de fazer autoescola, mas, como agora estava ajudando nas contas em casa, não sobrava dinheiro suficiente para iniciar as aulas. Segundo o cliente, estava dividindo as contas com o irmão, mas, no final do mês, era ele quem pagava sozinho as despesas, pois o irmão não lhe entregava a sua parte; assim, o desejo de fazer autoescola ia ficando em segundo plano. Após contar isso ao grupo, duas participantes do grupo orientaram Daniel a agir de outras formas. Para uma delas, ele deveria se impor para sua família, nem que, para isso, tivesse que lutar ou "brigar" pelo seu espaço. A outra participante, por sua vez, comentou que, às vezes, para não causar confusão, ficamos calados, mas com isto acabamos perdendo muito mais do que quando reclamamos ou falamos. Assim, ela aconselhou Daniel a entregar a sua parte da conta à mãe e esperar que o irmão contribuísse também. Após estas conversas, uma terceira participante aconselhou Daniel a "jogar tudo pra cima”, no sentido de não fazer o que as pessoas esperavam dele. Daniel afirmou que este jeito explosivo é algo muito diferente para ele, mas contou que uma vez ele conseguiu seguir sua própria vontade e "jogar tudo pra cima”, colocando um piercing sem pedir permissão para sua família.

Ao escutar este fato, tive a impressão que colocar um piercing era um acontecimento muito diferente da narrativa dominante apresentada até então por Daniel. Em outras palavras, o fato de ele "ter jogado tudo pra cima" e colocado o piercing era um acontecimento extraordinário passado. Desta forma, buscando identificar tal acontecimento e ampliá-lo, me mantive numa postura de curiosidade para convidá-lo a pensar sobre o que de especial aconteceu nesta situação que não acontecia nas outras. Assim, me interessei em saber mais sobre sua história do piercing, buscando compreender o que havia ajudado Daniel a agir desta forma e se ele conseguia pensar na contribuição desta experiência para sua vida. Este, por 
sua vez, pontuou que, nesta situação, havia pensado menos na opinião das outras pessoas e se permitido olhar mais para ele. $\mathrm{O}$ participante afirmou, então, que na época se sentiu vitorioso ao colocar o piercing, pois isto representava um momento de independência com relação à influência da família nas suas escolhas.

Quando busquei explorar o acontecimento em que Daniel colocou o piercing e contrariou a sequência de sua relação dependente com a família, não somente sua fala, mas também toda a conversa no grupo passou a ser focalizada no sentido de se poder pensar um futuro diferente para Daniel, referente, então, à decisão por realizar um curso universitário.

Desta forma, analisando-se o processo conversacional desencadeado pela identificação e ampliação de um acontecimento extraordinário, podemos perceber a utilidade desta ferramenta no contexto clínico. Buscando ampliar tais acontecimentos com Daniel, a conversa no grupo começou a tomar um novo rumo e o "Daniel que antes estava numa posição estática”, sem perspectivas, vai se re-descrevendo como um "novo Daniel”.

Nas perspectivas construcionistas aplicadas à psicoterapia, o terapeuta busca ampliar e criar com as pessoas em atendimento novas possibilidades e sentidos. Neste caso, Daniel contou um acontecimento que não fazia parte da sua narrativa dominante, saturada pelo problema, mas, quando este acontecimento passou a ser identificado e ampliado, a narrativa de Daniel pôde, aos poucos, ser ressignificada, abrindo espaços que, até então, não pareciam possíveis.

“A HISTÓRIA DO APARELHO DENTARIO”: IDENTIFICANDO UM ACONTECIMENTO EXTRAORDINARIO PRESENTE

$\mathrm{Na}$ quinta sessão, por meio do uso da carta terapêutica, destacamos que havíamos percebido que na sessão anterior Daniel estava com aparelho dentário e ficamos curiosos para saber o que havia motivado tal conquista. $\mathrm{O}$ participante havia nos contado em outras sessões que desejava realizar muitos projetos e atividades, mas que nem sempre isso era possível, pois, como estava ajudando em casa, não lhe sobrava dinheiro para concretizar seus sonhos. Em virtude disso, usamos a carta terapêutica como uma possível ferramenta para convidar Daniel a refletir sobre o que poderia ter lhe ajudado a tomar a decisão de colocar o aparelho e quais recursos ele possuía que poderiam ter permitido que agisse desta forma.

Respondendo ao convite da carta, Daniel contou que marcou um horário no dentista, consultou, colocou o aparelho e só depois comunicou para a família o fato. Em virtude disso, busquei ampliar este acontecimento extraordinário pre- 
sente e conectar este fato com a situação em que ele colocou o piercing. Daniel, por sua vez, afirmou que agiu da mesma forma que na situação de antes e que ainda tinha vontade de colocar um piercing novamente. Contou, também, que escutou os conselhos de uma das participantes do grupo e que recentemente deu a sua contribuição para o pagamento das despesas na sua casa e estava tranquilo com relação a isso, pois antes queria assumir até as responsabilidades que não eram dele. No entendimento de Daniel, ao colocar o aparelho e não se preocupar se faltaria dinheiro para o pagamento das contas, ele estava "jogando tudo para cima”, como havia proposto uma das participantes do grupo. Em virtude dessa afirmação, busco entender melhor como foi para ele agir desta forma. O participante respondeu que se sentiu bem, mas que nem sempre é possível "jogar tudo para cima”; ou seja, é preciso avaliar cada situação. Neste momento, Daniel começou a construir um novo sentido: nem sempre dá para agir como se planeja, mas é preciso experimentar o jeito que cabe melhor para cada ocasião.

A partir destas conversas e da identificação e ampliação de um acontecimento extraordinário, vão sendo construídos, junto com este participante e com todo o grupo, novos sentidos para a vida de Daniel. Desta maneira, ele, aos poucos, vai criando um senso de autoria, em que não precisa sempre ser o dependente, aquele que não tem autonomia de escolhas; pode tomar as próprias decisões, se arriscar e decidir sobre o que o outro lhe propõe. Quando Daniel entende que pode colocar os seus desejos na frente dos desejos de sua família, bem como quando não aceita o "jogar tudo para cima” proposto por uma das participantes como o único jeito de se resolver os problemas, ele vai procurando um novo espaço, um novo lugar nas suas relações que contribui para a construção de uma nova narrativa, em que passa a ocupar o lugar daquele que age conforme deseja e não somente como os outros escolhem para ele.

“O SURGIMENTO DE NOVOS RECURSOS PARA O ENFRENTAMENTO DAS SITUAÇŌES”: UMA TENTATIVA DE EXTERNALIZAR A INSEGURANÇA E A ANSIEDADE

Após a conversa e a identificação do acontecimento extraordinário presente - colocar o aparelho dentário - na quinta sessão, busquei investigar se o participante tinha novos projetos para seu futuro. Daniel, por sua vez, comentou novamente que desejava ingressar na universidade, fazendo um curso universitário que envolvesse artes e comunicação. Ele também contou que tinha percebido que, normalmente, ouvia muito os comentários e as opinióes das outras pessoas e isso tinha lhe dificultado ao tomar decisōes e fazer escolhas. Afirmou ainda que 
se considerava muito inseguro e ansioso e que esta ansiedade o atrapalhava para concluir o que começava. Uma participante, ao ouvir isso, respondeu a Daniel que o mais importante era tentar, mesmo que ele pensasse que não ia dar certo, pois não se pode prever o resultado das coisas antes de elas acontecerem.

Observando o fluxo da conversa, busquei externalizar (White \& Epston, 1990) esta insegurança descrita por Daniel. Assim, primeiro, procurei entender a influência do problema na sua vida, perguntando-lhe sobre o tamanho desta insegurança e o impacto que ela tinha nas suas relações; em seguida, busquei saber sobre a influência dele na vida do problema, questionando-o sobre como ele esperava que pudesse diminuí-la. Daniel, por sua vez, descreveu a insegurança como algo que o comprometia muito e que buscava aliviá-la escrevendo sobre como se sentia frente a isso.

Em seguida, outra participante do grupo contou uma situação em que se sentia muito ansiosa. Conectando-se ao comentário da participante, Daniel também se descreveu como ansioso, destacando que, quando está na fila para esperar um ônibus, fica pensando no lugar em que poderá se sentar quando o transporte chegar, de que jeito poderá agir ao entrar no veículo. Também comentou que, quando vai sair com alguma pessoa, fica agitado e preocupado, pensando se a outra pessoa irá aceitar ou não sair com ele, bem como em que lugar poderiam passear, para onde poderiam sair. Ao escutar isso, busquei, numa postura de curiosidade, investigar este jeito de agir de Daniel, perguntando quais os prós e os contras de se comportar desta forma. Daniel respondeu apenas que ficar mais pensativo tem lhe ajudado a repensar certos jeitos de agir. Apesar de Daniel não ter comentado sobre as suas formas de pensar que lhe causavam ansiedade, entendi que essa postura de repensar os jeitos de agir descrita por ele poderia ser um recurso que pudesse lhe ajudar a criar novas narrativas.

Após esta conversa, uma outra participante do grupo contou uma história em que se comparava com sua irmã mais velha. Em vista disso, Daniel comentou com esta participante que já se sentiu "o patinho feito" da sua casa, mas que agora havia parado de se comparar com os irmãos, percebendo que isso não era algo bom, pois, ao nos compararmos com pessoas que consideramos melhores, costumamos nos sentir piores. Através deste posicionamento, Daniel vai, aos poucos, criando uma narrativa em que está se percebendo como uma pessoa mais autônoma, segura, que se descreve como alguém que está tendo controle sobre si mesmo.

Apesar de não ter ocorrido uma externalização, propriamente dita, da insegurança e da ansiedade de Daniel, vemos que apostar nestas práticas foi muito importante para a criação de um contexto na conversa em que Daniel podia perceber recursos e situações nas quais conseguiu encontrar outros jeitos para lidar melhor 
com o que estava acontecendo. Assim, é importante que o terapeuta esteja sensível às implicações das ferramentas que ele utiliza para proporcionar novas conversas com as pessoas que participam do atendimento. Neste caso, o exercício da externalização do problema convidou Daniel a refletir sobre potencialidades positivas e sobre recursos que ele poderia utilizar para lidar melhor com certas situações. Daniel, assim, começou a construir a narrativa de um "Daniel mais autônomo", seguro, com o agenciamento da própria história.

Por meio das ideias construcionistas, o terapeuta desenvolve uma conversa propositada em que se busca promover reflexões e ampliar sentidos. Para cada pessoa se usa um recurso, uma ferramenta, um jeito de conversar diferente. $\mathrm{Na}$ conversa com Daniel, o mais importante não foi o conteúdo (a insegurança ou ansiedade), mas o processo de construção de novos sentidos para a sua vida que surgiram por meio da conversa destes conteúdos. Assim, no construcionismo, o terapeuta não assume o papel de um especialista no conteúdo das falas das pessoas, mas no processo conversacional, que é construído por meio da relação cliente-terapeuta (Anderson \& Goolishian, 1998; Grandesso, 2000).

\section{“A MUDANÇA DA MUDANÇA”: FORTALECENDO A NARRATIVA DE ENFRENTAMENTO}

Da nona sessão de terapia em diante, Daniel passou a trazer uma narrativa de enfrentamento, em que ele se descrevia como alguém mais independente e autônomo. Buscando entender melhor e fortalecer esta narrativa em que ele se considerava como uma pessoa que estava encontrando novos jeitos de agir, incentivei o participante a conversar sobre suas mudanças. Neste movimento, Daniel se mostrou como uma pessoa que estava mais contente, que se sentia melhor e que desejava não regredir ao antigo jeito de ser.

Tentando ainda ampliar esta conversa e esta nova narrativa, questionei Daniel sobre o que ele poderia fazer para se manter neste novo jeito. Curiosamente, ele comentou que não gostaria de permanecer usando os novos recursos que descobriu com a terapia para se relacionar com as pessoas e lidar com as situações, mas que desejava crescer, melhorar e progredir. Investi nesta conversa de forma a questionar o que ele poderia fazer para continuar crescendo. $\mathrm{O}$ participante, então, comentou que buscava a "mudança da mudança", ou seja, a criação constante de novos jeitos para lidar com as pessoas e as situações. Desta forma, esta nova descrição representou um grande passo na história de Daniel, pois inicialmente ele se descrevia como alguém inserido numa rotina, que não lhe fazia bem, com dificuldades de pensar sobre novas possibilidades para sua vida. 
A mudança do participante do grupo foi construída durante as sessões, bem como legitimada não só pelos terapeutas, mas também pelas outras pessoas do grupo e por sua própria família. De acordo com Daniel, a própria família estava percebendo a sua mudança: antes do começo do atendimento ele estava desempregado, logo após o início da terapia arrumou um emprego; anteriormente, não tinha muitas perspectivas para o futuro, não tinha disposição para estudar, agora estava fazendo um curso técnico e pensava na possibilidade de fazer uma universidade; durante a terapia, começou a fazer aulas de autoescola e colocou o aparelho dentário. Além disso, os outros participantes do grupo também destacavam e reconheciam que Daniel havia mudado, pois agora estava mais falante e participativo das conversas do grupo. Esse processo de legitimação contribuiu para o fortalecimento da nova narrativa construída junto com o participante, principalmente por esta mudança ter sido percebida e confirmada pela família, que era personagem marcante na narrativa anterior de sofrimento usada por ele. Assim, com o processo de legitimação, a mudança vai se concretizando e fazendo parte das narrativas de Daniel que, agora, se descrevia como aquele que conseguia defender as próprias ideias, bem como era capaz de desenvolver alguns planos e projetos para o futuro.

Como foi comentado no início deste trabalho, nos encontros finais da terapia as conversas de legitimação das narrativas de enfrentamento geradas no contexto grupal permitem maior visibilidade, tanto para o terapeuta como para seus clientes, de todo o processo de construção e de fortalecimento da mudança (Rasera \& Japur, 2007).

\section{CONSIDERaÇŌES FINAIS}

Na história de Daniel, podemos perceber uma pessoa que começou a terapia com a descrição de alguém que não tinha muitas perspectivas, que ficava a maior parte do tempo na frente do computador, sem trabalhar e estudar, e se sentia dependente das opiniôes da família e concluiu o atendimento com novas perspectivas e sonhos e com a sensação de maior autonomia e independência. Os momentos significativos dessa história de mudança por nós recortada foram: a) "o dia do piercing"; b) "a história do aparelho dentário"; c) "o surgimento de novos recursos para o enfrentamento das situaçōes"; e d) "a mudança da mudança".

Ao analisarmos este processo de mudança construído no grupo, buscamos dar visibilidade a como as intervençôes pautadas pela perspectiva narrativa podem contribuir para a criação de novas possibilidades de vida no contexto grupal. As intervenções realizadas nos trechos recortados consistiram em: a) identificação de 
acontecimento extraordinário passado; b) identificação de acontecimento extraordinário presente; c) externalização do problema; e d) fortalecimento da narrativa de enfrentamento.

De acordo com a perspectiva narrativa, os problemas são criados por meio de narrativas que buscam dar sentido à vida das pessoas e, no entanto, geram sofrimento. Desta forma, a terapia narrativa tem como proposta desconstruir histórias dominantes que impedem as pessoas de se relacionarem e viverem, bem como desenvolver com os clientes narrativas mais ricas e preferidas sobre si mesmos e suas vidas. Nesse atendimento analisado, as práticas narrativas ajudaram a criar na relação terapeuta-cliente, bem como nas conversas do grupo, um fluxo conversacional que permitiu novas possibilidades para a vida de um participante do grupo.

Apesar de buscarmos dar visibilidade a algumas formas de intervenção narrativa, é importante destacar que não se trata de uma proposta terapêutica que prescreve um modelo de atendimento pautado no uso pragmático de determinadas técnicas, com indicações para populações e sintomas específicos. Ao contrário, trata-se de uma postura interpretativa, orientada pela analogia textual (White $\&$ Epston, 1990).

Nesse sentido, entendemos que o mais importante é o terapeuta assumir uma postura de engajamento na narrativa das pessoas atendidas de forma a valorizar e se interessar pelos conhecimentos e sentidos à medida que são criados e vivenciados pelas pessoas em suas conversas; isto é, o saber profissional deve ser uma ferramenta por meio da qual o terapeuta cria com as pessoas que atende novas possibilidades tanto para suas vidas quanto para o saber-fazer do profissional.

Desta forma, neste trabalho contamos a história de mudança de Daniel e como certos jeitos de se conversar podem contribuir para o processo de mudança das pessoas em atendimento terapêutico. Além disso, destacamos a importância e o uso das propostas narrativas para o campo da psicoterapia de grupo. Ao utilizarmos as propostas narrativas no âmbito do espaço do grupo, pudemos perceber como elas criaram espaços dialógicos que permitiram aos clientes conversarem sobre suas dificuldades, compartilharem suas vivências e ressignificarem suas histórias.

Contudo, esta aproximação ainda traz um desafio relativo, especialmente, à tensão indivíduo-grupo no processo terapêutico. De forma geral, as intervenções narrativas parecem se adequar facilmente à transformação da narrativa de um membro do grupo, cabendo aos outros participantes do grupo atuarem como colaboradores, a convite do terapeuta. Este uso das contribuiçôes da terapia narrativa, apesar de útil e pertinente, pode, em alguns casos, promover inadvertidamente um enfoque individualista. Desconsiderar-se-ia, assim, o potencial disruptivo e transformador da terapia narrativa, ocultando a dimensão cultural das narrativas 
de sofrimento e desvalorizando o grupo como um contexto privilegiado para tal investigação. Cabe ao terapeuta convidar o grupo a identificar e refletir sobre as implicaçōes de determinadas metáforas e vocabulários sociais tal como encarnados nas narrativas pessoais, contribuindo para a tarefa de desconstrução de algumas verdades normalizadoras e opressivas sustentadas pelo discurso grupal.

Esperamos que a história deste atendimento possa ajudar terapeutas e profissionais de Psicologia no exercício criativo e reflexivo de construção e invenção da prática clínica no sentido de incentivá-los a uma atuação sensível ao processo de construção de sentidos. As narrativas, no nosso entendimento, são ferramentas culturais que estão disponibilizadas socialmente e são utilizadas pelas pessoas para dar sentidos às suas experiências. Por isso, acreditamos que cabe ao terapeuta o exercício de ajudar seus clientes a construir novas possibilidades de forma a criarem um repertório mais rico de sentidos e não serem apenas usuários e reprodutores de narrativas que promovam confinamentos e sofrimentos.

\section{REFERÊNCIAS}

Anderson, H. \& Goolishian, H. (1998). O cliente é o especialista: a abordagem terapêutica do não-saber. In: McNamee, S. \& Gergen, K. J. (orgs.). A terapia como construção social (pp. 35-50). Porto Alegre: Artes Médicas.

Chen, M., Noosbond, J. P. \& Bruce, M. A. (1998). Therapeutic document in group counseling: an active change agent. Journal of Counseling and Development, 76, 404-411.

Epston, D., White, M. \& Murray, K. (1998). Proposta de uma terapia de reautoria: revisão da vida de Rose e comentário. In: McNamee, S. \& Gergen, K. J. (orgs.). A terapia como construção social (pp. 117-139). Porto Alegre: Artes Médicas.

Freedman, J. \& Combs, G. (1996). Narrative therapy: the social construction of preferred realities. New York/London: W. W. Norton \& Company.

Gergen, K. J. (1997). Realities and relationships: soundings in social construction. Cambridge: Harvard University Press.

Grandesso, M. (2000). Sobre a reconstrução do significado: uma análise epistemológica e hermenêutica da prática clínica. São Paulo: Casa do Psicólogo.

Laube, J. \& Treftz, S. (2004). Group therapy using a narrative theory framework: application to treatment of depression. Journal of Systemic Therapies, 13(1), 29-37.

Lax, W. D. (1998). O pensamento pós-moderno na prática clínica. In: McNamee, S. \& Gergen, K. J. (orgs.). A terapia como construção social (pp. 86-105). Porto Alegre: Artes Médicas.

Rasera, E. F. \& Japur, M. (2001). Contribuiçōes do pensamento construcionista para o 
estudo da prática grupal. Psicologia. Reflexão e Crítica, 14(1), 201-209.

Rasera, E. F. \& Japur, M. (2004). Desafios da aproximação do construcionismo social ao campo da psicoterapia. Estudos de Psicologia, 9(3), 431-439.

Rasera, E. F. \& Japur, M. (2007). Grupo como construção social: aproximaçôes entre construcionismo social e terapia de grupo. São Paulo: Vetor.

Spink, M. J. (2003). Psicologia social e saúde: práticas, saberes e sentidos. Petrópolis: Vozes. White, M. \& Epston, D. (1990). Médios narrativos para fines terapéuticos. Buenos Aires: Paidós.

White, M. (1995). Re-authoring lives: interview \& essays. Adelaide: Dulwich Centre.

White, M. (2000). Reflections on narrative practice. Adelaide: Dulwich Centre.

White, M. (2007). Maps of narrative practice. New York: W. W. Norton \& Company.

\section{Notas}

1 Agradecemos a Daniel pela aprendizagem compartilhada, a Ana Luíza Bulkool Mantovani, a Camila Rosa Alvarenga e a Deise de Almeida Gomes, que trabalharam conosco neste atendimento. Agradecemos também à Profa. Dra. Paula Cristina Medeiros Resende que, gentilmente, contribuiu com sugestões e valiosos apontamentos durante a redação deste trabalho.

Recebido em 14 de fevereiro de 2009 Aceito para publicação em 07 de maio de 2010 